\title{
1993 Woody Award Goes to John Baglin
}

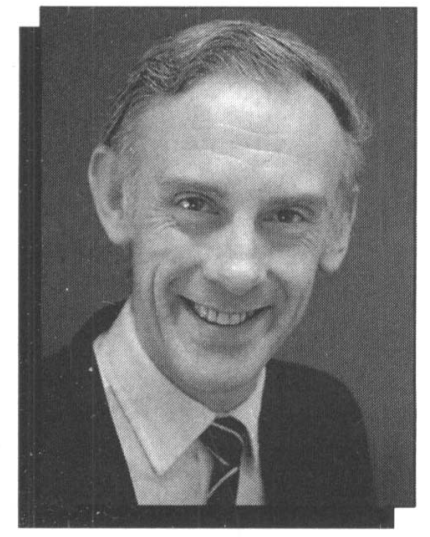

The 1993 Woody Award has gone to John Baglin, honoring the time and effort he has provided to the Materials Research Society. Offered "in recognition of outstanding service and dedication on behalf of MRS as exemplified by Woody White, MRS President, 1984," the award was presented to Baglin by 1993 MRS President Tom Picraux at the Council dinner during the 1993 Fall Meeting.

On receiving the Woody Award,
Baglin commented that it was the "most special thing I could imagine happening." He believes in the strong role MRS has in supporting researchers in the materials community. "Working with MRS is stimulating because of the vitality and energy of the people involved-both volunteers and the HQ staff. And it is rewarding because MRS can and does have a unique impact in the progress of materials research, which itself has so much to offer the world community today and in the very exciting future," he said.

Baglin was MRS president in 1988, a meeting chair in 1985. He has served as a councillor and symposium organizer, and has chaired various committees. As chair of the Publications Committee, "he was the force behind its existence," according to Picraux. Under Baglin, the committee initiated transfer of proceedings publication from Elsevier to MRS, and recommended initiation of Journal of Materials Research. The Awards Committee, which he currently chairs, has developed and initiated the MRS Medal and the Outstanding Young Investigator Award, and, with headquarters, developed the current awards brochure. He led the Long Range Planning Committee, developing methodology to generate a comprehensive 10-year MRS plan, and chaired a task force which formulated a plan for MRS electronic processing and network facilities.

"It's tremendous fun," Baglin said. "There will be plenty more years for me," he added, saying that it was Woody White himself who encouraged him to volunteer in and "make a difference" to MRS.

Baglin is at IBM's Almaden Research Center, where he manages materials physics research in the area of thin film interactions and characterization of materials surfaces and coatings. His research interests are ion beam modification of materials, ion beam analysis, and thin film interactions. In 1983, he co-organized an MRS symposium on Thin Film Interactions, and in 1988 was an organizer of a symposium on Thin Film Adhesion. His recent research has involved ion-beam-enhanced adhesion, such as metal on ceramic and copper on Teflon.

\section{Roy Receives Special Recognition at Fall Meeting}

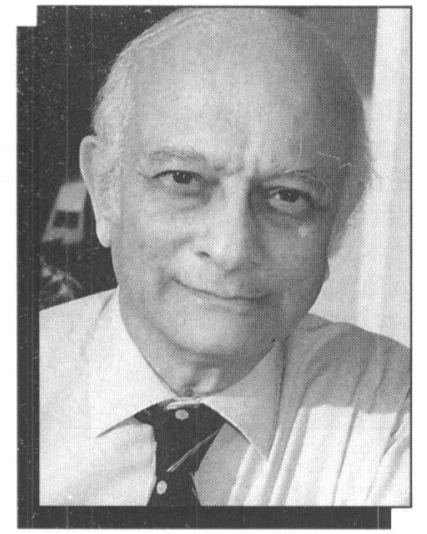

During the 1993 MRS Fall Meeting, when MRS celebrated the 20th anniversary of its first meeting, the MRS Council recognized the contributions of one of the Society's principal architects, Prof. Rustum Roy of Pennsylvania State University.

1993 MRS President Tom Picraux presented Roy with a unique symbol for his contributions-a brilliant-cut 750 carat "diamond" simulated in cubic zirconia.

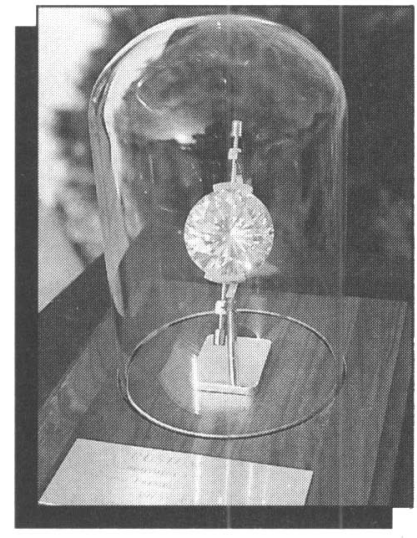

In making the presentation, Picraux emphasized that Roy had not only been a founder and visionary, but had continuously contributed to the vitality of the Materials Research Society over the past 20 years as officer, councillor, initiator of Symposium $X$, and in numerous other innovative ways. "We owe Rustum Roy a special debt of gratitude for his many outstanding and creative contributions to our Society," said Picraux.
Roy presented a historical review of the Materials Research Society, "Inventing and Re-inventing MRS," during Symposium $X$. He detailed the events leading to the founding of the Society by a small group of individuals from industry, national laboratories, and universities. It started with his own request to the National Research Council in 1967. This was followed by a succession of four national interdisciplinary meetings in the materials area from 1966 to 1972 . The meetings were organized by Penn State's Materials Research Laboratory. The first MRS meeting was held in Boston in 1973.

Roy's award was designed by 1993 MRS Secretary Lynn Boatner. Boatner conceived its design and arranged to have the parts handmade and put together. The gem, cubic stabilized zirconia, was grown by Ceres Corporation (Billerica, Massachusetts), a principal supplier of diamond substitutes. It was not faceted by hand, however, but by computer-driven equipment in Switzerland. The zirconia is held under the glass in a mineralspecimen holder.

MRIS 